\title{
Antisense oligonucleotides targeting c-fos mRNA inhibit rheumatoid synovial fibroblast proliferation
}

Yoshitaka Morita, Naoki Kashihara, Masahiro Yamamura, Hideyuki Okamoto, Seishi Harada, Masanori Kawashima, Hirofumi Makino

\begin{abstract}
Objective-To determine whether antisense oligonucleotides targeting c-fos mRNA have the ability to inhibit the growth of interleukin 1 (IL1) stimulated fibroblast-like cells from the synovium in rheumatoid arthritis (RA).

Methods-Fibroblast-like cells established from RA synovium were stimulated by IL1 with antisense or sense oligonucleotides complementary to c-fos mRNA, and the proliferation of these cells was determined by ${ }^{3} \mathrm{H}$-thymidine incorporation. Effect of antisense oligonucleotides on expression of activator protein 1 (AP1) activity was evaluated using electrophoretic mobility shift assay.

Results-C-fos antisense oligonucleotides inhibited IL1 stimulated synovial fibroblast proliferation. The expression of AP1 activity induced by IL1 was suppressed by treatment with antisense oligonucleotides. Conclusion-These results suggest the feasibility of antisense strategies designed to suppress c-fos expression as therapeutic agents for RA.
\end{abstract}

(Ann Rheum Dis 1998;57:122-124)

Rheumatoid arthritis (RA) is a chronic inflammatory disorder characterised by remarkable hyperplasia of synovial lining cells and pannus formation. A large amount of evidence indicates that an abnormal expression of several nuclear protooncogenes modulates the cellular proliferation of RA synovium. ${ }^{1}$ One of such genes is c-fos, which is an immediate early gene that is induced rapidly and transiently upon stimulation of quiescent cells with various mitogens. ${ }^{2}$ The transcriptional products of the fos and jun gene families form a heterodimeric transcription factor, activator protein 1 (AP1), which activates the several gene expression and regulates cellular biological activities including proliferation. ${ }^{3}$ In RA synovial tissues, constitutive expression of c-fos gene has been reported by several groups. ${ }^{4}$ Immunoreactivity for c-fos protein has been found in fibroblast-like cells, which are a major component of proliferating cells in RA synovium. ${ }^{5}$ Furthermore, the pathological importance of c-fos in RA was supported by the finding of destructive arthritis in c-fos transgenic mice. ${ }^{6} \mathrm{C}$-fos is thus thought be an appropriate target gene in the treatment of RA.

Recently, antisense therapy is expected to be effective in diseases in which overexpression of specific genes is involved in the pathophysiology. ${ }^{7}$ Oligodeoxynucleotides
(ODNs) complementary to mRNA of the target gene are utilised to specifically block the gene expression. We have previously shown that antisense ODNs designed to suppress the expression of proliferating cell nuclear antigen have the potential use as therapeutic agents to inhibit synovial cell growth in RA. ${ }^{8}$ In this study, we attempted to inhibit the proliferation of rheumatoid synovial fibroblasts by inhibiting the expression of c-fos, using antisense ODNs that are specific for c-fos mRNA.

\section{Methods}

SYNTHESIS OF ODNS

Antisense (5'-GAAGCCCGAGAACATCAT$\left.3^{\prime}\right)$ and sense (5'-ATGATGTTCTCGGG CTTC-3') phosphorothioate ODNs corresponding to the human c-fos cDNA sequence extending from the ATG initiation codon to 18 nucleotides downstream, were synthesised using an automated DNA synthesiser (model 380B, Applied Biosystems, Foster City, CA, USA). ODNs were purified by column chromatography, lyophilised, and dissolved in culture media. The concentration of each ODN was determined spectrophotometrically.

PREPARATION OF RHEUMATOID SYNOVIAL

FIBROBLASTS

Synovial fibroblasts were obtained as previously described. ${ }^{9}$ In brief, synovial tissues obtained during joint surgery from RA patients were treated with collagenase and DNase for one hour at $37^{\circ} \mathrm{C}$. Dispersed synovial cells were cultured at $37^{\circ} \mathrm{C}$ in a humidified atmosphere containing $5 \% \mathrm{CO}_{2}$ in Dulbecco's modified Eagle's medium (DMEM; Life Technologies, Gaithersburg, MD, USA) supplemented with $10 \%$ heat inactivated fetal calf serum (Life Technologies), $25 \mathrm{mmol} / 1$ HEPES (Life Technologies), $100 \mathrm{IU} / \mathrm{ml}$ penicillin, and $100 \mu \mathrm{g} / \mathrm{ml}$ streptomycin. Cells were split weekly when primary cultures had reached confluence. These cells were found to be morphologically homogeneous fibroblast-like cells, and were used between the fourth and eighth passages.

CULTURE AND PROLIFERATION ASSAY OF SYNOVIAL FIBROBLASTS

Synovial fibroblasts were allowed to adhere overnight at $37^{\circ} \mathrm{C}$ at a density of $1 \times 10^{5} / \mathrm{ml}$ in $100 \mu \mathrm{l}$ of DMEM with $10 \%$ fetal calf serum in 96 well flat bottomed microtitre plates (Costar Corp, Cambridge, MA, USA). The medium was replaced with DMEM with $1 \%$ fetal calf serum and $10^{-5} \mathrm{~mol} / 1$ indomethacin (Wako Pure Chemical Ind, Osaka, Japan) in the presence of $1 \mathrm{ng} / \mathrm{ml}$ of recombinant human 


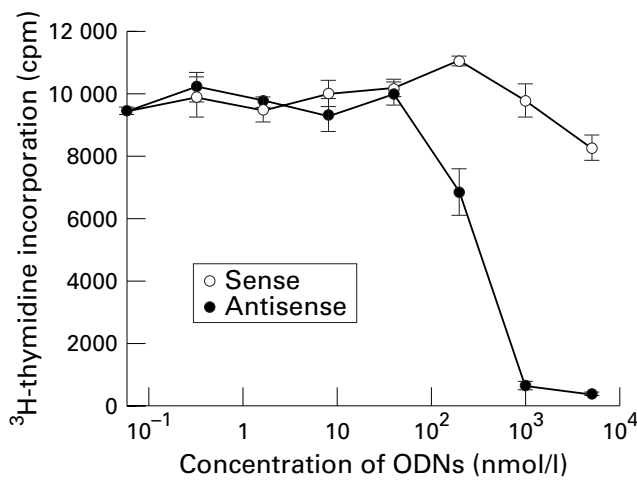

Figure 1 Antisense oligodeoxynucleotides (ODNs) targeting $c$-fos $m R N A$ inhibit the proliferation of synovial

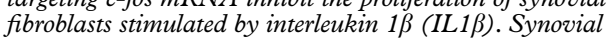
fibroblasts were cultured for 72 hours containing serially diluted sense or antisense ODNs with IL1及 $(1 \mathrm{ng} / \mathrm{ml})$. ${ }^{3} \mathrm{H}$-thymidine incorporation during the last 12 hour pulse of cultures was determined. Data are expressed as the mean (SEM) cpm in triplicate cultures.

interleukin $1 \beta$ (IL1 $\beta$, Otsuka Pharmaceutical Co, Tokushima, Japan) and sense or antisense ODNs in triplicate wells. Liposome was used to facilitate the transfection of ODNs into cells. ${ }^{8}$ Sense or antisense ODNs were mixed with 10 $\mu \mathrm{g} / \mathrm{ml}$ of lipofectin reagent (Life Technologies) and incubated for 20 minutes at room temperature. The ODN-liposome complexes were added dropwise to each well. Cells were further cultured for 72 hours at $37^{\circ} \mathrm{C}$ in a humidified atmosphere containing $5 \% \quad \mathrm{CO}_{2}$ with a last 12 hour pulse of $1 \mu \mathrm{Ci}$ of ${ }^{3} \mathrm{H}$-thymidine (Amersham Corp, Tokyo, Japan) per well. After removal of the medium, cells were treated with a solution of trypsin-EDTA for 30 minutes. Detached cells were harvested using an automated cell harvester, and radioactivity was countered in a liquid scintillation counter.

For detection of AP1 binding ability, synovial fibroblasts were plated overnight at a density of $1 \times 10^{5} / \mathrm{ml}$ in $2 \mathrm{ml} \mathrm{DMEM}$ with $10 \%$ fetal calf serum in a 24 well microtitre plate (Costar Corp). Cells were then treated with 5 $\mu \mathrm{mol} / 1$ of sense or antisense ODN-liposome complexes in DMEM with $0.5 \%$ fetal calf serum for 24 hours. After stimulation with IL1 $\beta$ ( $1 \mathrm{ng} / \mathrm{ml})$ for 24 hours, they were harvested to obtain nuclear extracts for electrophoresis mobility shift assay (EMSA).

ISOLATION OF NUCLEAR EXTRACTS AND EMSA Nuclear extracts were isolated according to the method of Schreiber et al. ${ }^{10}$ Briefly, cells were collected, washed with TRIS buffered saline and incubated with buffer A ( $10 \mathrm{mmol} / \mathrm{l}$ HEPES, $\mathrm{pH}$ 7.9, $10 \mathrm{mmol} / 1 \mathrm{KCl}, 0.1 \mathrm{mmol} / 1 \mathrm{EDTA}, 0.1$ $\mathrm{mmol} / \mathrm{l} \mathrm{EGTA,} 1 \mathrm{mmol} / 1$ dithiothreitol (DTT), $0.5 \mathrm{mmol} / 1$ phenylmethylsulfonyl fluoride (PMSF)) for 15 minutes at $4^{\circ} \mathrm{C}$. Then $10 \%$ solution of Nonidet P-40 was added, and the cells were mixed vigorously and centrifuged. Nuclear pellets were suspended with buffer B (20 mmol/1 HEPES, pH 7.9, $400 \mathrm{mmol} / 1 \mathrm{NaCl}$, $1 \mathrm{mmol} / 1 \mathrm{EDTA}, 1 \mathrm{mmol} / 1 \mathrm{EGTA}, 1 \mathrm{mmol} / 1$ DTT, $1 \mathrm{mmol} / 1 \mathrm{PMSF}$ ), mixed for 15 minutes at $4^{\circ} \mathrm{C}$ and centrifuged. The protein concentration of nuclear extract was determined by the
Bio-Rad protein assay kit (Bio-Rad Laboratories, Hercules, CA, USA).

EMSA was then performed as follows. Synthetic double strand oligonucleotides (5'CGCTTGATGAGTCAGCCGGAA-3'; 3'GCGAACTACTCAGTCGGCCTT-5') containing AP1 binding sequence were labelled at $5^{\prime}$ end with $\gamma-{ }^{32} \mathrm{P}$-ATP (Amersham Corp). Three $\mu \mathrm{g}$ nuclear extracts and $0.45 \mathrm{ng}$ of ${ }^{32} \mathrm{P}$-labelled probe were mixed in binding buffer (4\% glycerol, $1 \mathrm{mmol} / 1 \mathrm{MgCl}_{2}, 0.5 \mathrm{mmol} / 1$ EDTA, $0.5 \mathrm{mmol} / 1 \mathrm{DTT}, 50 \mathrm{mmol} / 1 \mathrm{NaCl}, 10$ $\mathrm{mmol} / \mathrm{l}$ TRIS-HCl, $\mathrm{pH}$ 7.5, $0.05 \mathrm{mg} / \mathrm{ml}$ poly $(\mathrm{dI}-\mathrm{dC}))$. Binding reaction mixture was incubated for 20 minutes at room temperature. The samples were run onto a $4 \%$ native polyacrylamide gel, and the gel was dried and subjected to autoradiography analysis.

To confirm the specificity of the AP1 probe, we performed the preliminary experiments of cold competition and immunodepletion assays. A 50-fold excess of unlabelled AP1 probe caused an elimination of the AP1 binding activity in synovial fibroblasts induced by IL1 $\beta$. For the immunodepletion assay, nuclear extracts were incubated with $1 \mu \mathrm{g}$ of rabbit polyclonal anti-Fos antibody (Santa Cruz Biotechnology, Santa Cruz, CA, USA) for 60 minutes at $4^{\circ} \mathrm{C}$ before EMSA. This pretreatment inhibited the AP1 binding activity.

\section{STATISTICAL ANALYSIS}

The statistical significance of differences in response was assessed by two way analysis of variance.

\section{Results}

We first examined the effect of antisense ODNs targeting c-fos mRNA on the proliferation of IL $1 \beta(1 \mathrm{ng} / \mathrm{ml})$ stimulated synovial fibroblasts. Figure 1 shows representative data of three separate experiments using cells from three different RA patients. The proliferative response to IL $1 \beta$ was significantly inhibited by $c$-fos antisense ODNs ( $p<0.0001)$. Maximal inhibition $(>90 \%)$ was obtained with antisense ODNs at a concentration of $1 \mu \mathrm{mol} / \mathrm{l}$. In contrast, sense ODNs showed no inhibitory effect on the cell proliferation. In addition, no cytotoxity of antisense or sense ODNs was found at the concentration used in this study (data not shown).

To determine the effect of c-fos antisense ODNs on the expression of the target protein, nuclear extracts were prepared from synovial fibroblasts treated with IL1 $\beta$ in the presence of sense or antisense ODNs and binding ability of AP1 was assessed by EMSA. As shown in figure 2, AP1 binding ability induced by IL1 $\beta$ was suppressed in cells treated with c-fos antisense ODNs compared with cells treated with sense ODNs.

\section{Discussion}

Although the overgrowth of synovial fibroblasts is responsible for the rheumatoid joint destruction, effective therapeutic strategies to inhibit this chronic proliferation of synovial cells have not been available. Much evidence indicates that the process of this abnormal cellular
$A P 1$ binding ability was examined by electrophoretic mobility shift assay. 
growth in RA synovium may involve constitutive expression of $\mathrm{c}-\mathrm{fos},{ }^{4-6}$ which has been known to play a central part in cellular growth. ${ }^{23}$ More recently, it has been reported that the activity of AP1 (c-fos/c-jun heterodimer) is also up regulated in synovium of RA compared with osteoarthritis, and correlates with the expression of c-fos mRNA in situ. ${ }^{11}$ In this study we demonstrated that the growth of rheumatoid synovial fibroblasts was inhibited through the suppression of c-fos protooncogene expression by using antisense ODNs complementary to c-fos mRNA. This result provides further understanding of the important role of c-fos in the synovial fibroblast growth, and suggests that antisense ODNs targeting c-fos might be a promising therapeutic agent for RA.

The expression of AP1 activity induced by IL1 was considerably suppressed by treatment with c-fos antisense ODNs. C-fos/AP1 is well known to regulate gene expression of matrix degrading enzymes such as collagenase and stromelysin, ${ }^{12}$ which have been reported previously to be increased in rheumatoid joints and have been discussed extensively about their importance for joint destruction. ${ }^{15}$ In fact, administration of the double strand ODNs containing the AP1 consensus sequence reduces gene transcription for matrix degrading enzymes in the inflamed synovium of collagen induced arthritis, and inhibits the joint destruction. ${ }^{13}$ Taken together, c-fos antisense ODNs might be expected to prevent joint destruction by not only inhibiting the cellular growth but also blocking the production of matrix degrading enzymes through the suppression of AP1 activity.

Our previous study revealed that the inhibitory effect of antisense ODNs is mediated through decreases in the expression of both mRNA and protein. ${ }^{8}$ In this study, we evaluated the effect of c-fos antisense ODNs on expression of the target protein by examining the activation of AP1 using EMSA. The specificity was supported by the finding that antisense ODNs inhibited the expression of AP1 activity, but sense ODNs had no effect. We cannot completely eliminate the possibility at present that this effect is a consequence of several unknown effects of the antisense ODNs. ${ }^{14}{ }^{15}$ However, the most probable explanation is that antisense ODNs specifically bind to the targeted complementary sequences of the c-fos message and lead to the specific decrease of c-fos mRNA level or its translation, and eventually suppression of AP1 formation.

We used cationic liposome to facilitate the transfection of ODNs into cells. Without using liposome, $50 \%$ inhibition of the cell proliferation was obtained with antisense ODNs at a concentration of 5 to $10 \mu \mathrm{mol} / 1$ (data not shown). In contrast, $50 \%$ inhibition was obtained by using cationic liposome with antisense ODNs at a concentration of 0.2 to 1 $\mu \mathrm{mol} / 1$ as shown in figure 1 . In addition, we have previously demonstrated that fluorescein labelled ODNs with liposome enter the nucleus of $>95 \%$ of the cells. ${ }^{8}$ These results suggested that cationic liposome improves trans- fection efficiency and reduces the dosage of antisense ODNs to achieve the inhibition of cell growth.

Recent clinical trials of RA treatment that interfere with the effects of inflammatory cytokines such as IL1 and tumour necrosis factor $\alpha$ seem to be very attractive to cool down the local inflammation. The next step of therapeutic approaches should be to develop new agents with effectiveness for the rheumatoid joint destruction. Antisense ODNs targeting c-fos expression would be such strategy. However, there are several problems to be overcome before successful in vivo applications of antisense strategy. ${ }^{16}$ We need to develop drug delivery systems to administer ODNs efficiently and non-toxically to the inflamed synovium to modulate the local gene expression. It is also necessary to develop less cytotoxic and more stable modification of ODNs, because modified ODNs, especially phosphorothioate ODNs, often exert nonspecific effects. We believe our strategy with antisense ODNs to suppress the local c-fos/ AP1 function contributes to the development of effective agents to prevent the chronic joint destruction in RA.

1 Gay S, Gay R E, Koopman W J. Molecular and cellular mechanisms of joint destruction in rheumatoid arthritis: two cellular mechanisms explain joint destruction. Ann Rheum Dis 1993;52:S39-47.

2 Greenberg M E, Ziff E B. Stimulation of 3T3 cells induces transcription of the c-fos proto-oncogene. Nature 1984; 311:433-8.

3 Angel P, Karin M. The role of Jun, Fos and the AP-1 complex in cell-proliferation and transformation. Biochim Bioplex in cell-proliferation and tran

4 Dooley S, Herlitzka I, Hanselmann R, Ermis A, Henn W, Remberger $\mathrm{K}$, et al. Constitutive expression of $\mathrm{c}-\mathrm{fos}$ and c-jun, overexpression of ets-2, and reduced expression of metastasis suppression gene $\mathrm{nm} 23-\mathrm{H} 1$ in rheumatoid arthritis. Ann Rheum Dis 1996;55:298-304.

5 Trabandt A, Aicher W K, Gay R E, Sukhatme V P, Fassbender H-G, Gay S. Spontaneous expression of immediately-early response genes c-fos and egr-1 in collagenase-producing rheumatoid synovial fibroblasts. Rheumatol Int 1992;12:53-9.

6 Shiozawa S, Tanaka Y, Fujita T, Tokuhisa T. Destructive arthritis without lymphocyte infiltration in $\mathrm{H} 2$-c-fos transgenic mice. J Immunol 1992;148:3100-4.

7 Wagner R W. Gene inhibition using antisense oligodeoxynuWagner R W. Gene inhibition using ant
cleotides. Nature 1994;372:333-5.

8 Morita Y, Kashihara N, Yamamura M, Okamoto H, Harada S, Maeshima Y, et al. Inhibition of rheumatoid synovial fibroblast proliferation by antisense oligonucleotides targeting proliferating cell nuclear antigen messenger RNA. Arthritis Rheum 1997;40:1292-7.

9 Okamoto H, Yamamura M, Morita Y, Harada S, Makino H, Ota Z. The synovial expression and serum levels of interleukin-6, interleukin-11, leukemia inhibitory factor, and oncostatin $M$ in rheumatoid arthritis. Arthritis Rheum 1997;40:1096-105.

10 Schreiber E, Matthias P, Müller M M, Schaffner W. Rapid detection of octamer binding proteins with 'mini-extracts', prepared from a small number of cells. Nucleic Acids Res 1989;17:6419.

11 Asahara H, Fujisawa K, Kobata T, Hasunuma T, Maeda T, Asanuma $\mathrm{M}$, et al. Direct evidence of high DNA binding Asanuma $\mathrm{M}$, et al. Direct evidence of high DNA binding activity of transcription factor AP-1 in rheumatoic
synovium. Arthritis Rheum 1997;40:912-18.

12 Schönthal A, Herrlich P, Rahmsdorf H J, Ponta H. Requirement for fos gene expression in the transcriptional activation of collagenase by other oncogenes and phorbol esters. Cell 1988;54:325-34.

13 Shiozawa S, Shimizu K, Tanaka K, Hino K. Studies on the contribution of c-fos/AP-1 to arthritis joint destruction. J Clin Invest 1997;99:1210-16.

14 Yakubov L, Khaled Z, Zhnag L M, Truneh A, Vlassov V, Stein C A. Oligodeoxynucleotides interact with recombinant CD4 at multiple sites. J Biol Chem 1993;268: $18818-23$.

15 Perez J R, Li Y, Stein C A, Majumder S, Oorschot A V, Narayanan R. Sequence-independent induction of Sp1 ranscription factor activity by phosphorothioate oligode-

Kashihara N, Maeshima Y, Makino H. Therapeutic Intervention in glomerulonephritis by oligonucleotides. Exp Nephrol 1997;5:126-131. 